\title{
Team Semi Driver Dies after Rig is Struck by Impaired Driver
}

\section{Incident Number: 07KY091}

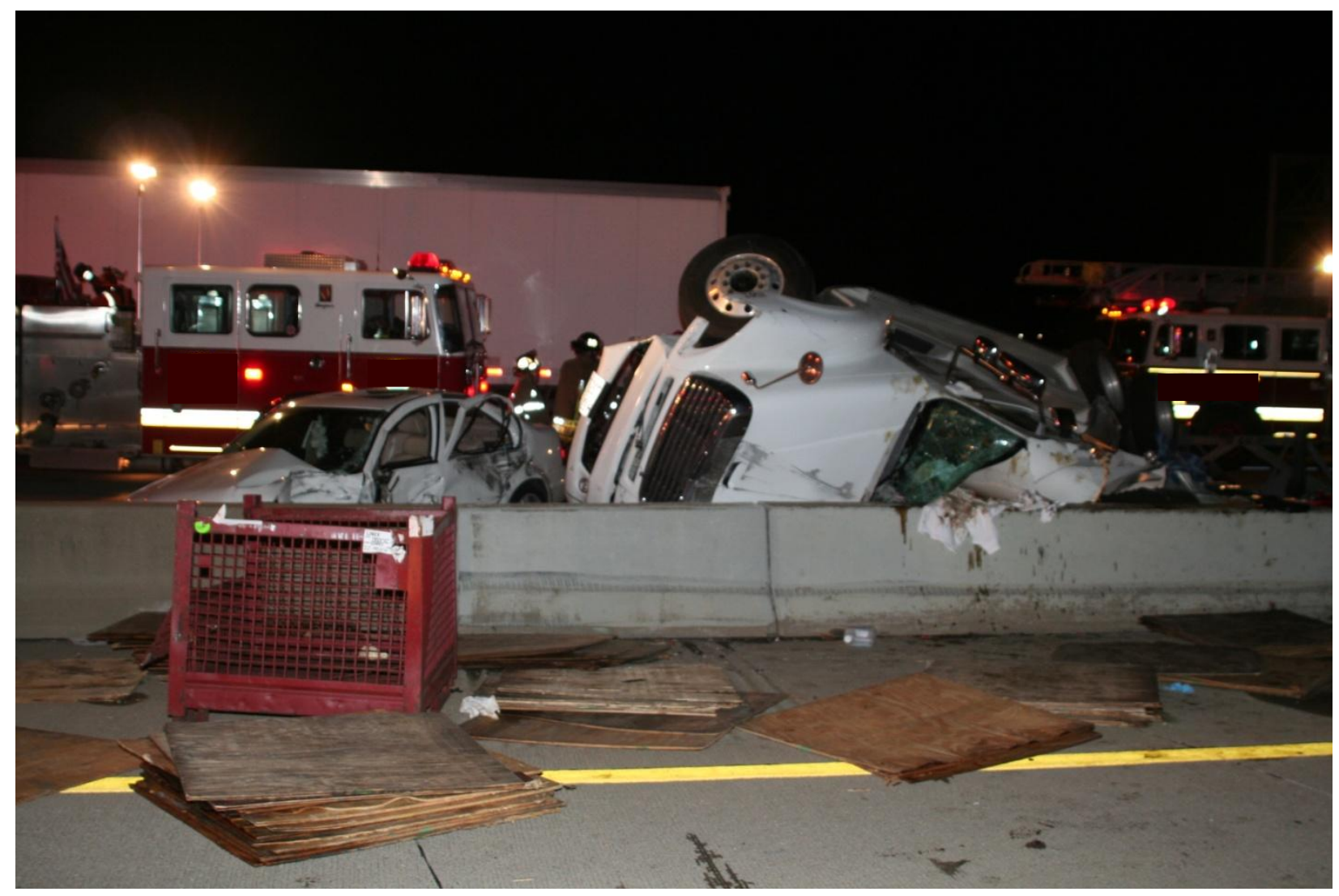

Photograph of semi and car involved in fatal crash. Photograph courtesy of law enforcement.

Kentucky Fatality Assessment and Control Evaluation Progran Kentucky Injury Prevention and Research Center 333 Waller Avenue

Suite 206

Lexington, Kentucky 40504

Phone: 859-323-2981

Fax: 859-257-3909

www.kiprc.uky.edu

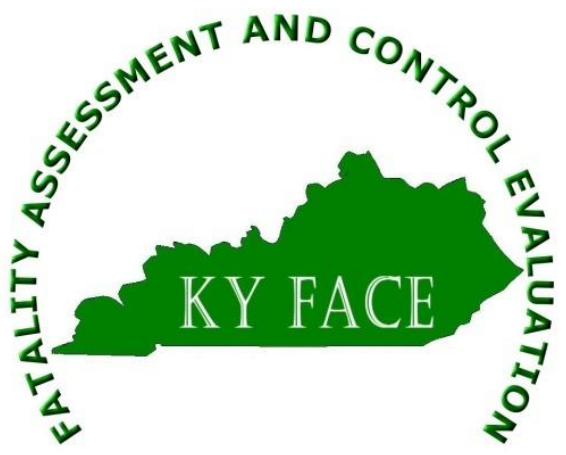




\section{Kentucky Fatality Assessment and Control Evaluation (FACE) Program \\ Incident Number: $\quad$ 07KY091 \\ Release Date: $\quad$ February 17, 2010 \\ Subject: Team Semi Driver Dies after Rig is Struck by Impaired Driver}

\section{Summary}

During the early hours one fall morning, a husband and wife driving team were traveling west on a divided interstate highway. A concrete barrier separated the four east bound lanes from the four west bound lanes. The wife was driving while the husband was asleep in the sleeper berth. Driving conditions were dark and the pavement dry. They were traveling in the second lane from the median and there was a passenger car to the right of the semi in the third lane from the median traveling next to the front wheel well and bumper. The passenger car driver veered into the front right wheel/ bumper area of the semi. In an attempt to avoid the car, the semi driver steered to the left, but the car struck the semi's right steering wheel. The passenger car driver tried to steer away from the semi, but the car was stuck in the wheel well. The semi and the passenger car, crossed the left travel lane and shoulder. The semi tractor-trailer struck the barrier wall, and jackknifed; the trailer flipped over the concrete barrier twisting the semi into a barrel roll onto its top. The husband was ejected from the semi truck and died at the scene. The driver of the passenger car was determined to have a blood alcohol level of $0.21 \mathrm{~g} / 100 \mathrm{ml}$ at the time of the incident.

To prevent future occurrences of similar incidents, the following recommendations have been made:

Recommendation No. 1: Underage drivers convicted of driving under the influence should be required to have an ignition diversion interlock device installed on their vehicle.

Recommendation No. 2: Passengers using the sleeper berth in a moving semi should use the restraint system currently provided by the manufacturer.

Recommendation No. 3: Concrete median barrier wall heights located in high traffic areas should be a installed at a height that prohibits tractor trailers from flipping over the barrier.

Recommendation No. 4: A safety needs assessment should be performed on the trucking industry.

\section{Background}

The husband and wife had been team drivers for six years and were employed by a transportation company in business since 1998. The trucking company delivered general, automotive, and refrigerated freight, which employed 10 drivers, and operated 10 semis, 10 trailers, and six refrigerated trailers.

Before becoming a commercial driving team, the couple farmed. To obtain their CDLs, the couple completed driver training courses on semi tractor operation including pre-trip and post- 
trip inspections, completion of all required paper work, and defensive driving techniques including skid pads training. The couple operated the same 2006 model semi each route and drove varied routes which took as long as 10 days.

\section{Investigation}

The Kentucky Fatality Assessment Control and Evaluation Program was notified via a governmental agency of a fatality involving a semi-truck driver who had been sleeping in the sleeper berth of the semi his wife was driving. A case evaluation was initiated, and a site visit was made. Police officers, a company representative, a towing company representative, and representatives from several governmental agencies were interviewed for this report.

The day before the incident, the husband and wife driving team picked up a semi tractor-trailer loaded with empty metal bins for the auto industry which were to be delivered approximately 650 miles away. They were to begin their dedicated, 1300 mile round-trip, two day route, the next day so they drove the tractor-trailer home in order to rest. The combined weight of the semi tractor-trailer and the wire bins was 54,000 pounds. At 6:00 PM the next evening, the husband and wife team commenced driving the route. The husband drove first and at 10:45 PM stopped and took a break until 12:30 AM. Upon completion of the break, the wife drove while the husband slept in the sleeper berth.

At approximately 1:50 AM, the tractor trailer was in the second right-hand lane headed west on an eight lane interstate which was divided by a concrete barrier wall. A passenger car, driven by an underage female, was traveling in the right hand lane next to the front of the semi when the car veered to the left into the front right tire/ fender area of the semi. To avoid the collision, the driver of the semi steered to the left, crossing the left travel lane and left shoulder, then struck the 3 feet 8 inch concrete median barrier wall.

When the semi struck the wall, the trailer jackknifed, slid over and down the concrete barrier wall, and struck a sign post and breaking apart discharging the contents of the trailer onto the highway. The semi tractor rolled upside down in a barrel roll, slid along the pavement and down the side of the wall breaking apart. The passenger car, stuck in the right steering wheel, was pushed by the semi along the concrete barrier wall. The semi and the passenger car came to rest with the passenger car 20 feet in front of the semi. The bunk in the sleeper berth came loose and the husband was ejected from the semi. He was found on the pavement by the barrier wall under wire crates from the trailer. The semi driver was found buckled upside down in the driver's seat.

Witnesses to the incident stated they observed the driver of the car weave then strike the right side of the semi. The passenger car driver was determined to have a blood alcohol level of 0.21 $\mathrm{g} / 100 \mathrm{ml}$ at the time of the incident. According to the accident reconstructionist, speed was not a factor in this incident.

\section{Cause of Death}

The cause of death was due to multiple blunt force injuries sustained in a motor vehicle collision with rollover and ejection. 


\section{Recommendations and Discussions}

\section{Recommendation No. 1: Underage drivers convicted of driving under the influence should be required to have an ignition diversion interlock device installed on their vehicle.}

Kentucky Revised Statute 189A.010 states that for a person 21 years of age or older, a blood alcohol level (BAC) of $0.08 \mathrm{~g} / 100 \mathrm{ml}$ or higher is legally intoxicated, and for persons under 21 years of age, $0.02 \mathrm{~g} / 100 \mathrm{ml}$ is legally intoxicated. The driver of the car involved in this incident was under 21 years of age with a blood alcohol content of $0.21 \mathrm{~g} / 100 \mathrm{ml}$ and was, therefore, legally intoxicated at the time of the incident. Five months prior to the crash, the driver of the car had a Under 21 Driving Under the Influence (DUI) charge, plead guilty, and entered an Under 21 DUI diversion program. Participants in the program must pay $\$ 60$, voluntarily lose their driving privileges for one month, participate in a victim impact course, perform volunteer work, attend alcohol treatment, attend ten Alcoholics Anonymous or Narcotics Anonymous meetings, and must remain free of new charges for one year. Any new charges result in removal from the Under 21 DUI diversion program and sentencing on the original Under 21 DUI charge. Participants have 12 months to complete the program steps.

A diversion interlock device that prevents a driver of a vehicle from driving under the influence of alcohol has been developed and a monitoring system is in place. Before starting a vehicle, this device requires the driver to blow into a tube and prevents the vehicle from starting if the driver has a $0.020 \mathrm{mg} / \mathrm{l}$ or above BAC. After the initial test to start the vehicle, the driver will be signaled within four to eight minutes to repeat the test. The driver will be signaled, thereafter, every ten to 30 minutes to repeat the test. If at any time the driver tests $0.020 \mathrm{mg} / \mathrm{l} \mathrm{BAC}$ or above, the vehicle is programmed to signal the driver to pull over and the ignition will turn off. At the time of this incident, obtaining the device and adequate monitoring of the device were issues that prevented the court from requiring the device to be installed on vehicles of drivers convicted of DUI. However, since this incident, the monitoring system for diversion interlock devices has been improved. The cost to install a diversion interlock device is approximately $\$ 80$, plus a deposit of $\$ 130, \$ 65$ for the first and last month lease fee. The monthly fee for the monitoring device is approximately $\$ 2.25$ a day, or $\$ 65$ a month, and includes a new testing device every two months. Test analyses are sent from the lab to the court. Analyses include date, time, and BAC. As access to this technology increases and monitoring capabilities improve, Kentucky should, as part of any underage DUI conviction, require a diversion interlock device to be installed in any vehicle that will be operated by the convicted driver.

Currently, 10 states require an installed ignition interlock device for all drivers convicted of drunk driving. Federal legislation was proposed on December 21, 2009, that will require all states to have laws by 2012 requiring an ignition interlock device for all drunk driver convictions. If a state fails to enact this legislation, a percentage of federal transportation funding will be withheld each year until the legislation is enacted.

Recommendation No. 2: Passengers using the sleeper berth in a moving semi should use the restraint system currently provided by the manufacturer. 
It is unknown if the restraints for the sleeper berth were used at the time of this incident, or because of the severity of the crash, if a restraint system would have prevented the occupant from being ejected from the semi. The Federal Motor Carrier Safety Administration standard number 393.76 pertaining to sleeper berths states that semi tractors manufactured on/ after July 1,1971 that are equipped with a sleeper berth must have an occupant restraint system. Currently, no standard requires the occupant of the sleeper berth to use the occupant restraint system.

A needs assessment survey should be performed on long-haul semi truck drivers who utilize sleeper berths. To our knowledge, no data exists on sleeper berth restraint usage among longhaul semi truck drivers. An informal survey of 20 long-haul truck drivers revealed that long-haul semi truck drivers do not use the sleeper berth occupant protection system while in the sleeper berth when the semi is in motion. When asked why the restraints were not being used, respondents answered that the sleeper berth occupant restraint system encumbered sleep. Sales personnel from three manufacturers, each with a minimum of 20 years of experience selling semis, were interviewed regarding the questions a potential buyer typically asks when purchasing a semi tractor. All three sales personnel stated that no potential buyer had ever asked them about the occupant restraint system in the sleeper berth. A custom sleeper cab designer was also interviewed for this report who stated that an owner/ operator had requested the designer to engineer a restraint system for the sleeper berth that would not encumber the occupant while sleeping, but would still restrain the occupant in case of a incident.

Sleeper berth occupant restraint systems manufactured by three different companies were evaluated for this report. All three manufacturers used a nylon webbing strap that snapped over the occupant in the sleeper berth. In two of the designs, the webbing strap created a triangle from the top of the sleep berth to the underside of the sleeper berth with the webbing as the hypotenuse. One design used the sleeper berth above to create a rectangle for the occupant to sleep in. Both designs allow for the occupant to be loosely restrained in the sleeper berth, thereby permitting movement of the occupant.

Possible solutions to restrain occupants in sleeper berths might include the fabrication of a privacy curtain/restraint system in the sleeper berth, installing an air bag above the mattress that would deploy toward the occupant upon certain conditions, or the use of heavy foam within the sleeper berth to insulate from noise and protect the sleeping occupant.

\section{Recommendation No. 3: Concrete median barrier wall heights located in high traffic areas should be a installed at a height that prohibits tractor trailers from flipping over the barrier.}

This incident occurred in a high traffic area where there was a 32 inch high concrete barrier wall to separate the two traffic directions. Trailer heights are usually 13 feet to 13.5 feet high. Concrete median barriers should be designed to prevent semis and trailers from flipping over the barrier. In this case, if the wall had been higher, the trailer could not have flipped over the wall, twisting the semi into a rollover. 


\section{Recommendation No. 4: A safety needs assessment should be performed on the trucking industry.}

Safety has greatly improved within the trucking industry over the past 30 years. Drivers tell us that the driver seats are more comfortable thus helping to reduce driver fatigue. Manufacturers have designed the dashboards to make the controls for the semi and trailer more convenient for the driver. Anti-lock brakes (49 CFR 393.55 anti-lock brake systems) are required on semis and buses manufactured after March 1, 1999. Vehicle stability assist systems that help eliminate roll-

overs and jackknifes are available for newer model semis and trailers. Manufacturers continue to evaluate how to make their semis and trailers better than the competitors. In order to help address unrecognized safety hazards, a needs assessment should be performed for the transportation industry.

\section{Keywords}

Alcohol

Drunk driving

Restraints

Semi tractor-trailer

Sleeper berth

\section{References}

1. Federal Motor Carrier Safety Administration Standard 49 CFR 393.76 Sleeper berths

2. The Drunk Driving Repeat Offender Prevention Act of 2009 (S. 2920), http://thomas.loc.gov/cgi-bin/query/z?c111:S.2920:

3. American Association of State Highway and Transportation Officials Roadside Design Guide, $3^{\text {rd }}$ Edition 2006

4. Kentucky Revised Statute 189A.010 Driving Under the Influence

5. Federal Motor Carrier Safety Administration Standard 49 CFR 393.55 anti-lock brake systems

\section{Acknowledgements}

Local coroner

Local police officers

Local prosecutor

Long haul truck drivers

Truck Driving Association

Semi manufacturers

Semi sales representatives 
The Kentucky Fatality Assessment \& Control Evaluation Program (FACE) is funded by a grant from the Centers for Disease Control and the National Institute of Safety and Health. The purpose of FACE is to aid in the research and prevention of occupational fatalities by evaluating events leading to, during, and after a work related fatality. Recommendations are made to help employers and employees to have a safer work environment. For more information about FACE and KIPRC, please visit our website at: www.kiprc.uky.edu

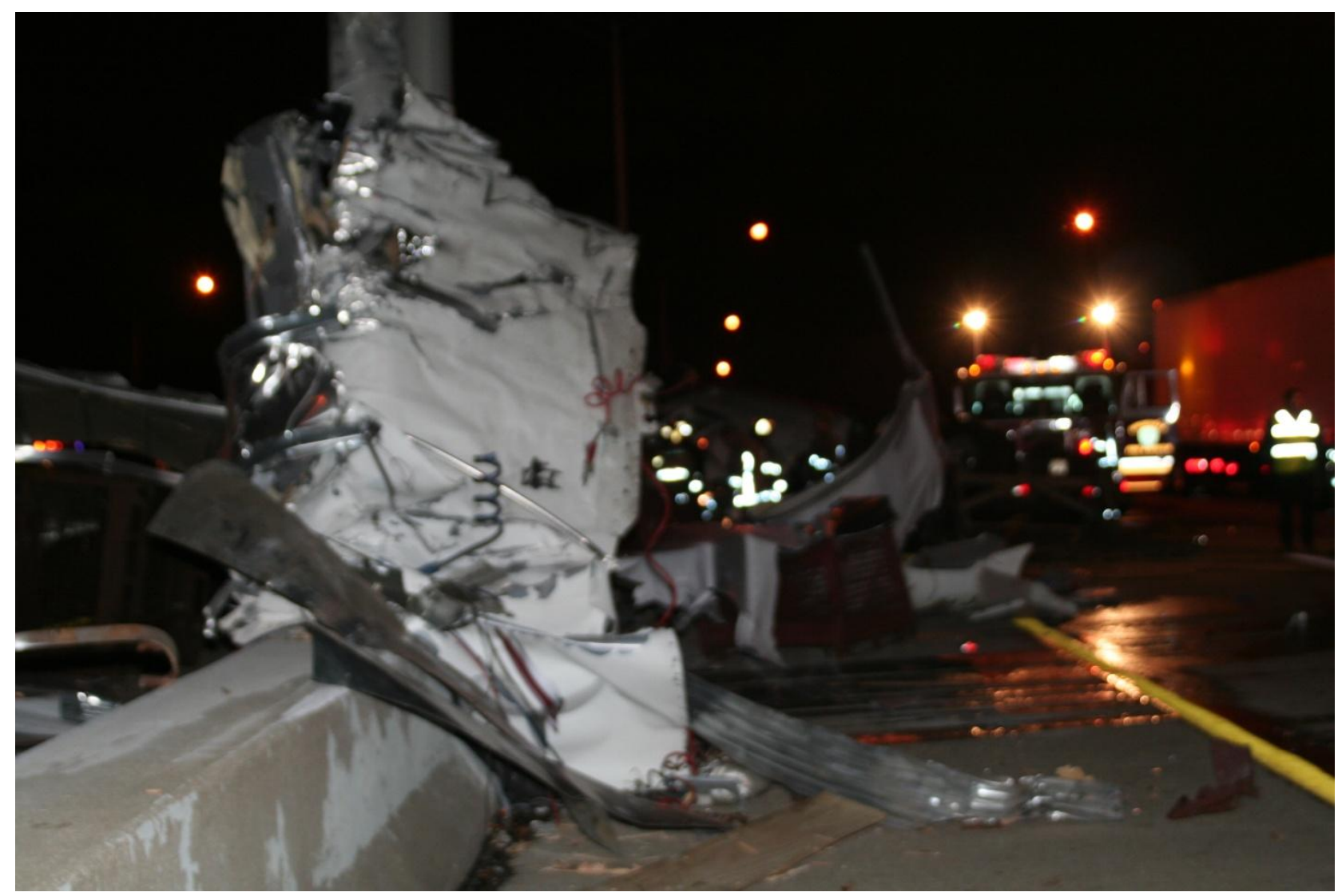

Photograph of trailer wrapped around sign pole. Photograph courtesy of law enforcement. 


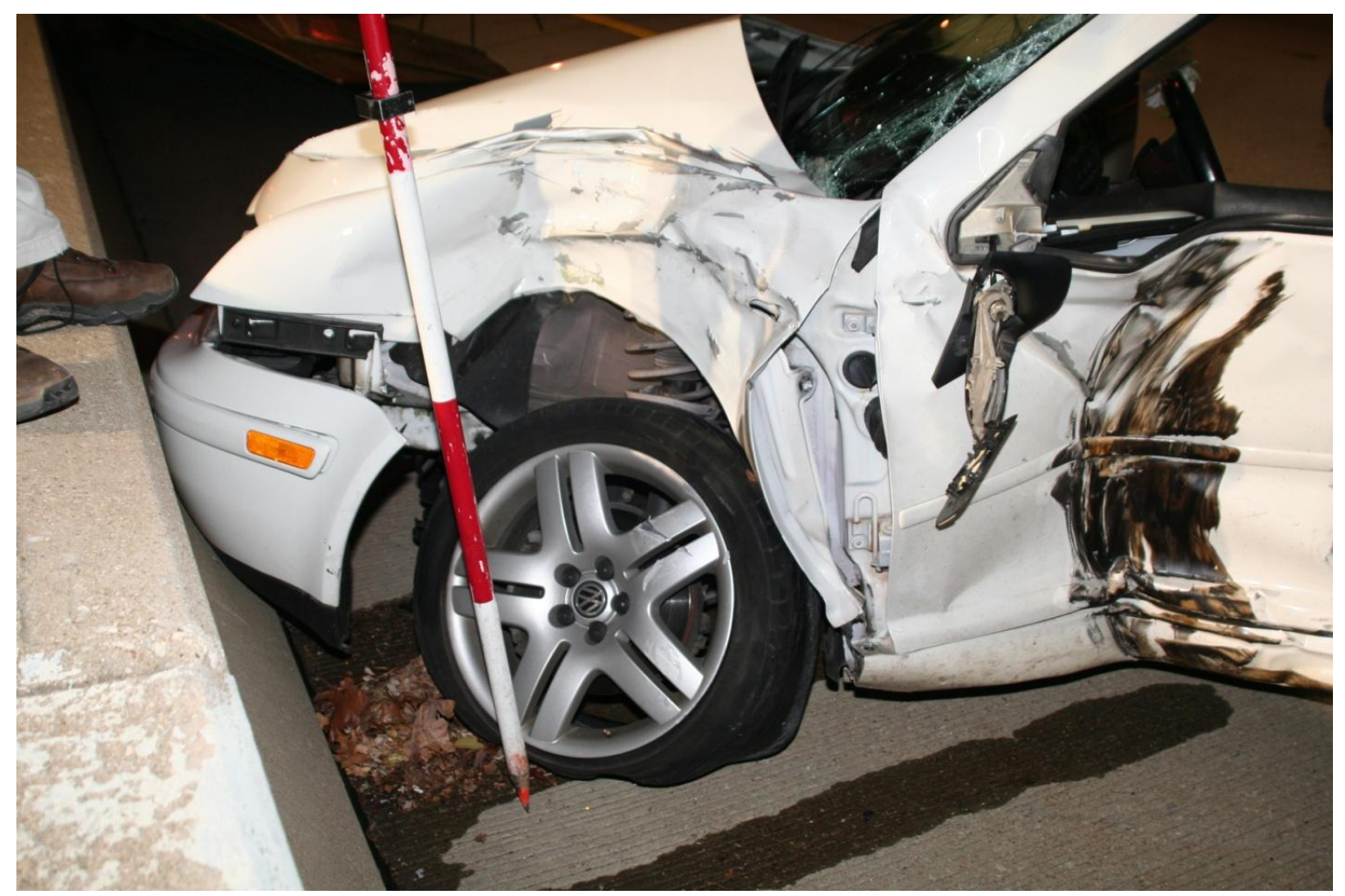

Photograph of car involved in crash. Photograph courtesy of law enforcement.

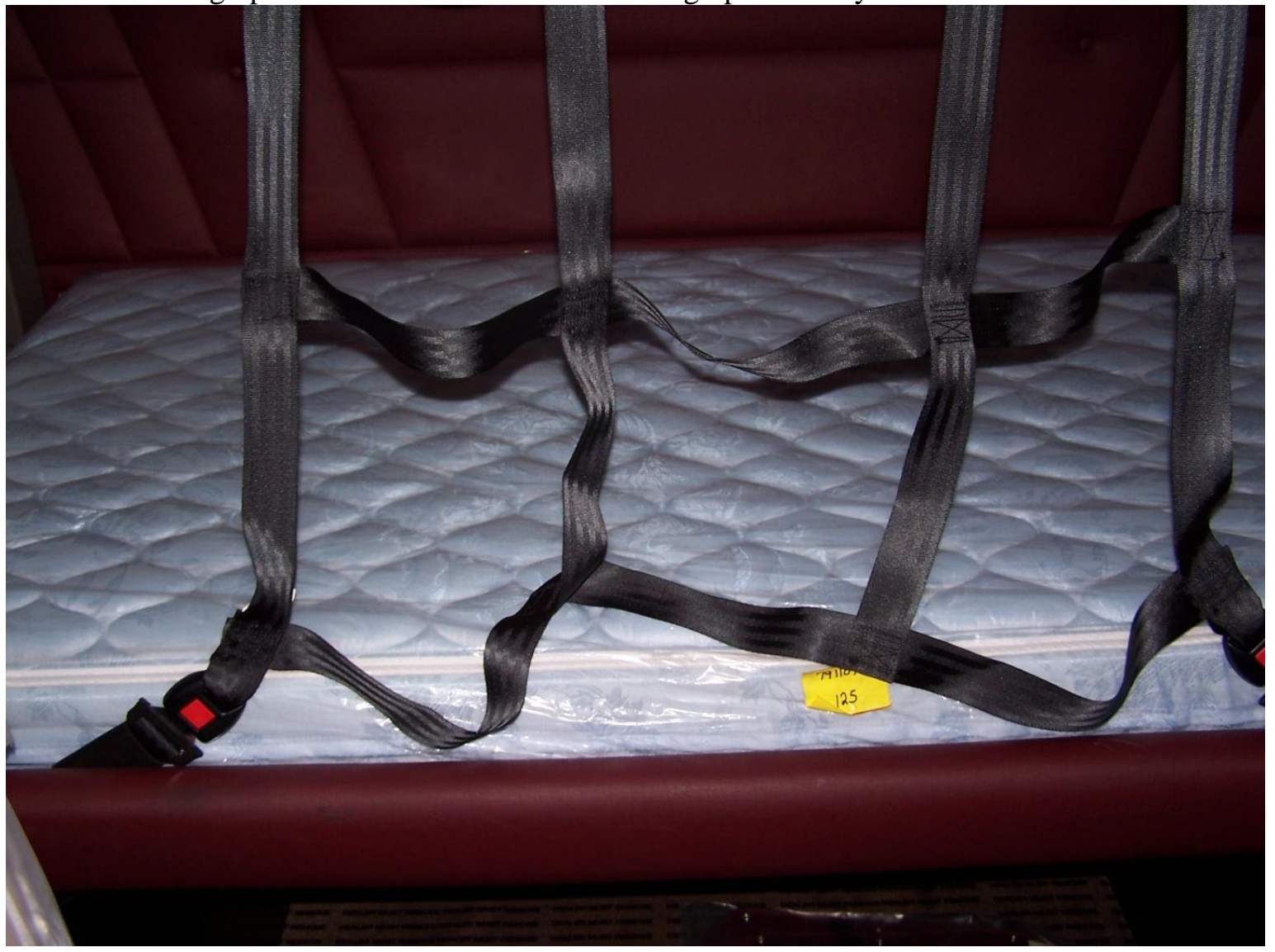

Photograph of a restraint system in a similar sleeper berth. Photograph by KY FACE. 